\title{
My friend Gil (1998)
}

\section{Ângelo Ferreira de Sousa}

Esferográfica preta sobre papel

Faculdade de Belas-artes

da Universidade do Porto

- afsousa@gmail.com

- www.angeloferreiradesousa.net

Dol https://doi.org/10.34913/

journals/lingua-lugar.2020.e213 
Portugal, 1998, seguindo os passos da vizinha Espanha, mas com uma prudente modéstia, Lisboa inaugura a sua Expo. A época é de festa, de especulação imobiliária e de banquetes de dinheiro público. Estes grandes eventos festivos internacionais precisam sempre de uma desculpa. Em Portugal, o pretexto é o mesmo de sempre: os descobrimentos portugueses, a vocação universalista e oceânica dos portugueses. Mas, apesar de tudo, os tempos são outros e em vez do "Mundo Português" festejam-se os "Oceanos". O Gil - a simpática mascote oficial - está em todo lado, em cada esquina, o amigo dos seus sponsors. Eu era estudante da escola de Belas Artes do Porto. Fazia desenhos em folhas A4 que depois fotocopiava e colava pela cidade. Era uma estratégia barata de curto-circuitar os percursos habituais das obras de arte, tanto os comerciais quanto os institucionais. A imagem do Gil abraçado a uma garrafa de um famoso refrigerante estadunidense - para o qual Álvaro de Campos escreveu um malogrado slogan publicitário - pareceu-me uma vítima ideal. A política externa dos EUA, e a sua longa história de campanhas bélicas, infelizmente sempre atual, era, aqui também, uma estratégia de ridicularizar a subserviência do pequeno Portugal.

Portugal, 1998, sur les traces de son pays voisin l'Espagne, mais avec une modestie prudente, Lisbonne ouvre son Expo. La période est marquée par la fête, la spéculation immobilière et les banquets d'argent public. Ces grands événements festifs internationaux ont toujours besoin d'une bonne excuse. Au Portugal, le prétexte est toujours le même : les "découvertes" portugaises, la vocation universaliste et maritime (océanique) des Portugais. 
Mais, malgré tout, les temps ont changé et au lieu du "Monde portugais" sont célébrés les "Océans". Gil - la gentille mascotte officielle - est partout, à chaque coin de rue, l'ami de ses sponsors. J'étais étudiant à l'école des beaux-arts de Porto. Je faisais des dessins sur des feuilles A4 que je photocopiais et collais dans toute la ville. C'était une stratégie bon marché pour court-circuiter les itinéraires habituels des œuvres d'art, tant commerciales qu'institutionnelles. L'image de Gil serrant dans ses bras une bouteille d'une célèbre boisson gazeuse américaine - pour laquelle Álvaro de Campos a écrit un slogan publicitaire maudit - me semblait une victime idéale. La politique étrangère américaine, et sa longue histoire de campagnes de guerre, malheureusement toujours d'actualité, était, ici aussi, une stratégie pour ridiculiser l'asservissement du petit Portugal.

Nas próximas 6 páginas são apresentados, pela respectiva ordem:

1. Tapete

2. Mon ami

3. Solo

4. Língua

5. Anjos

6. Fotocópia 


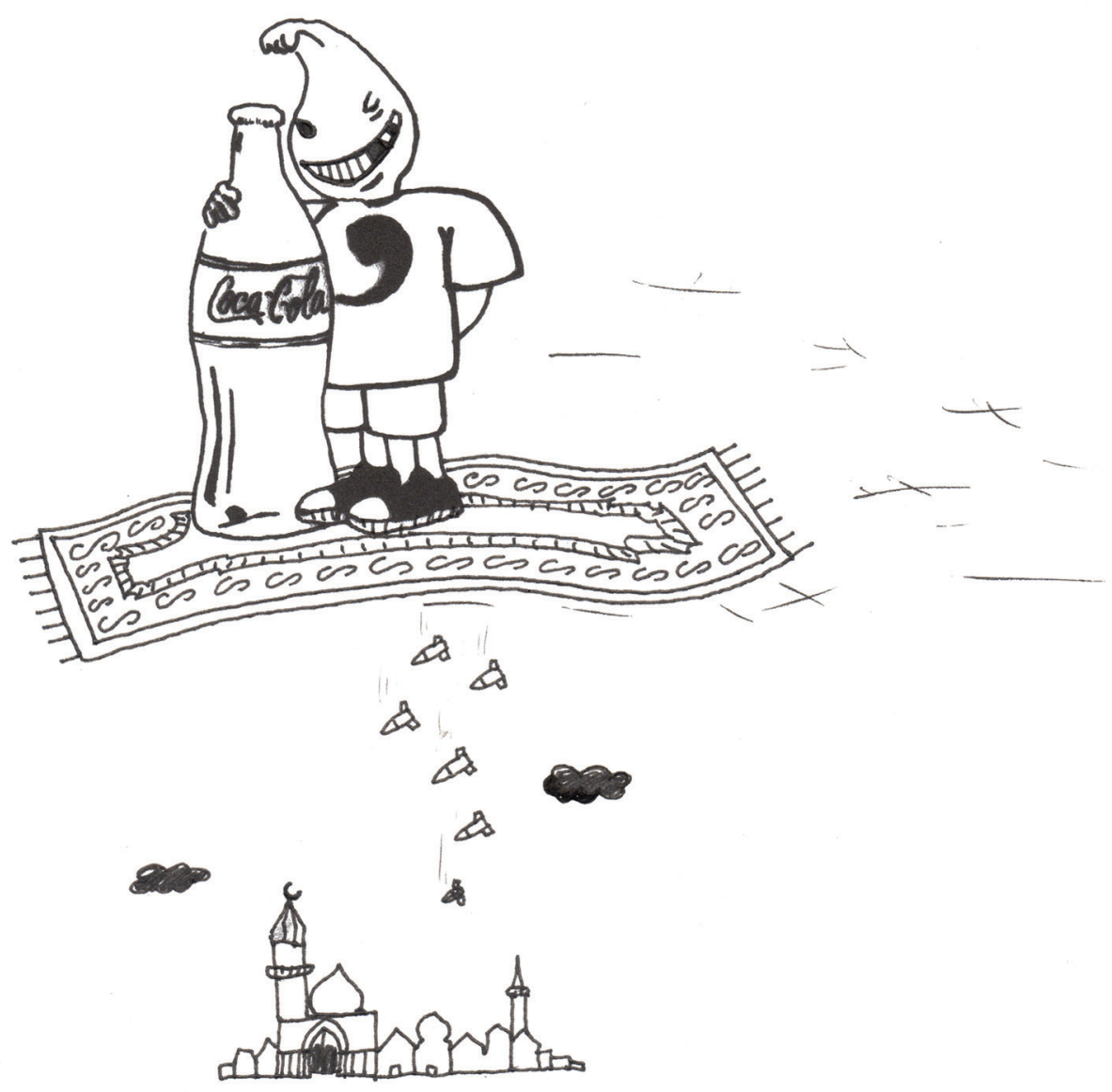




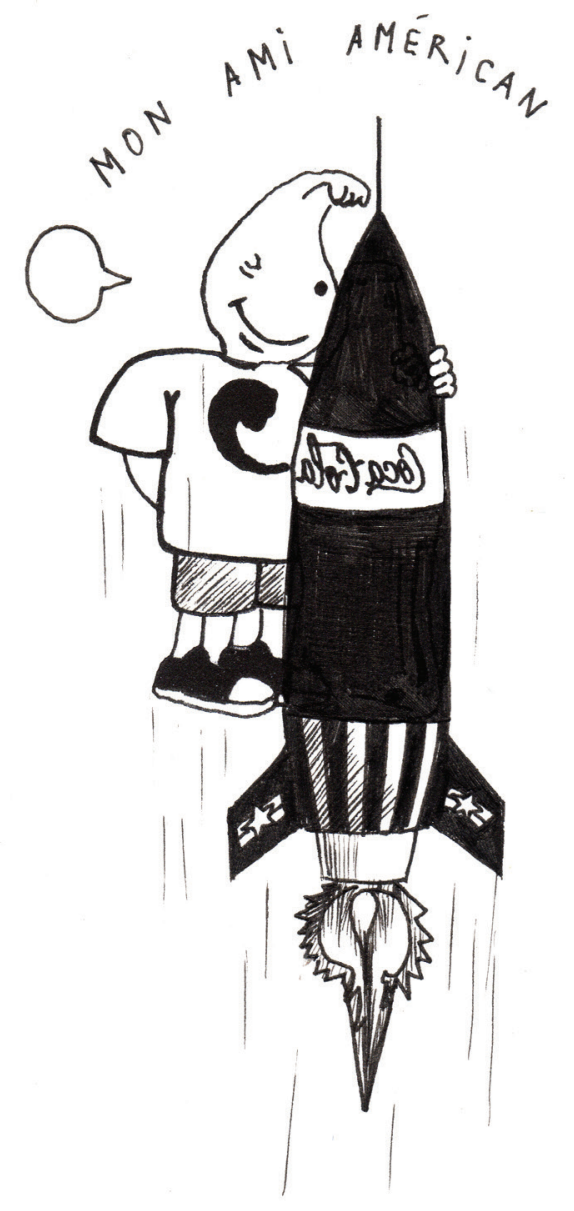



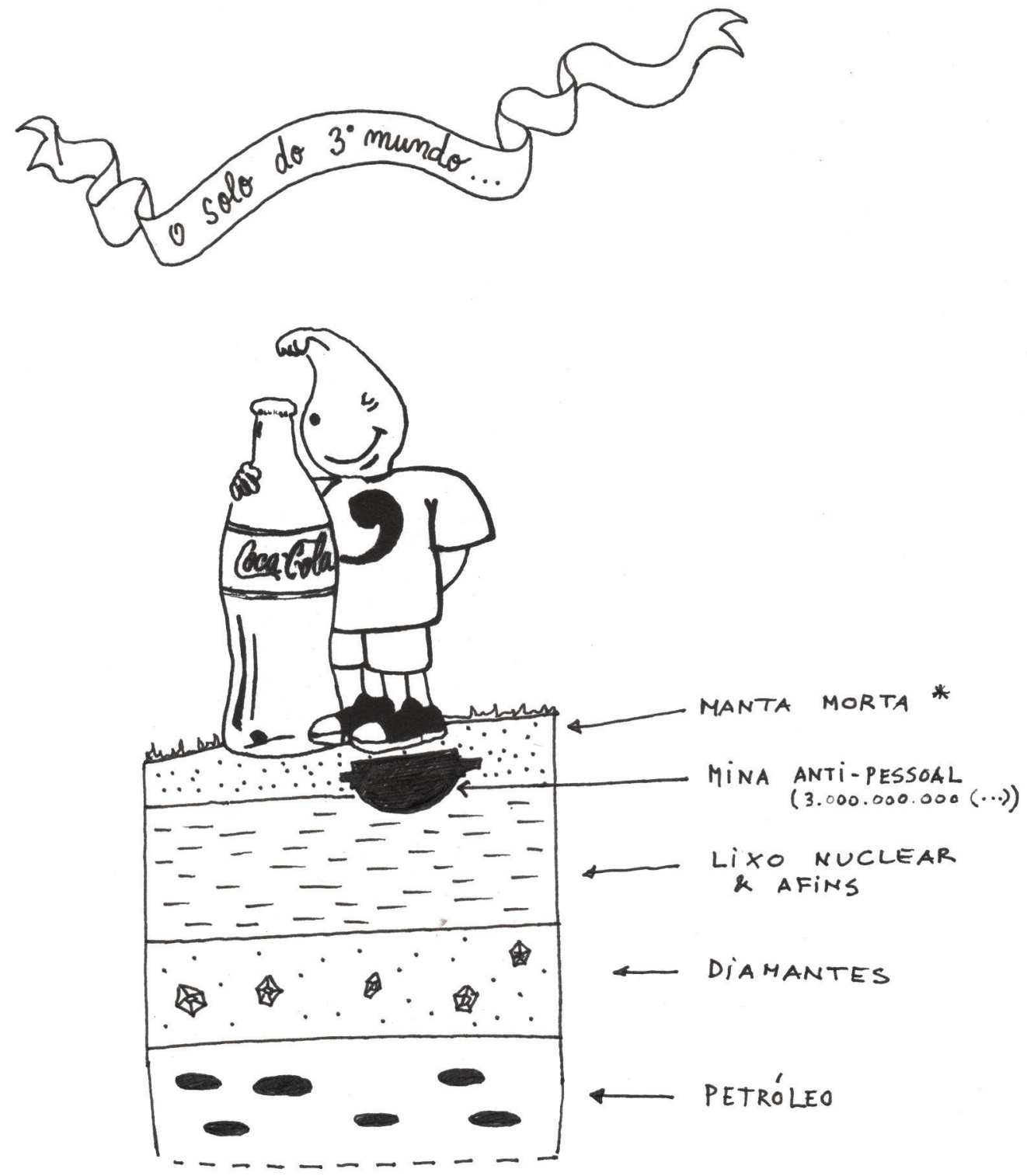

* (dissidentes politicos, revoltados e populacáa en geral) 


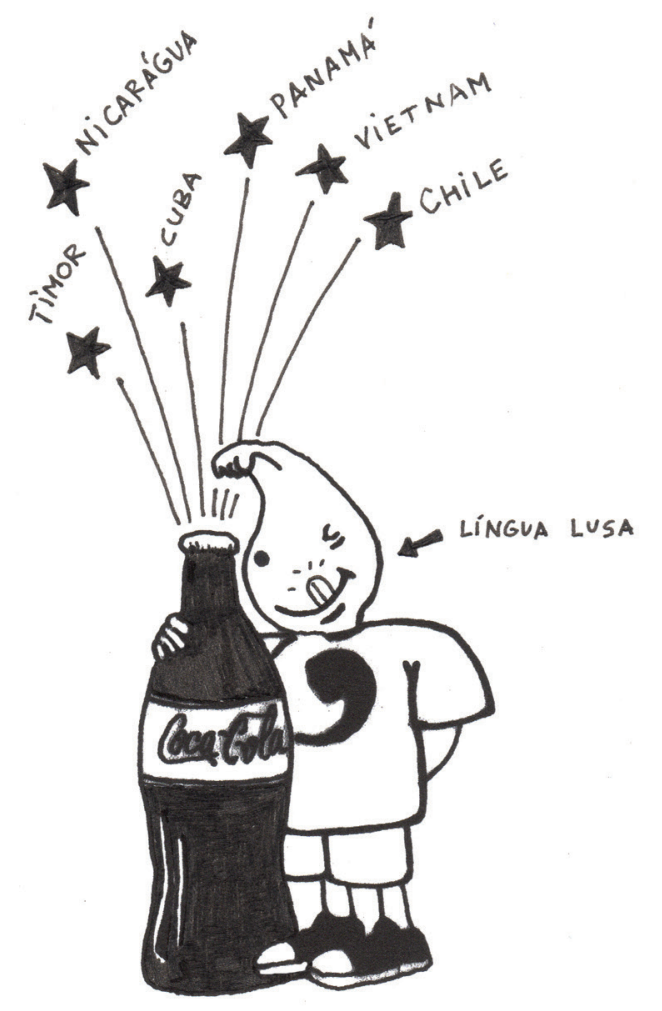




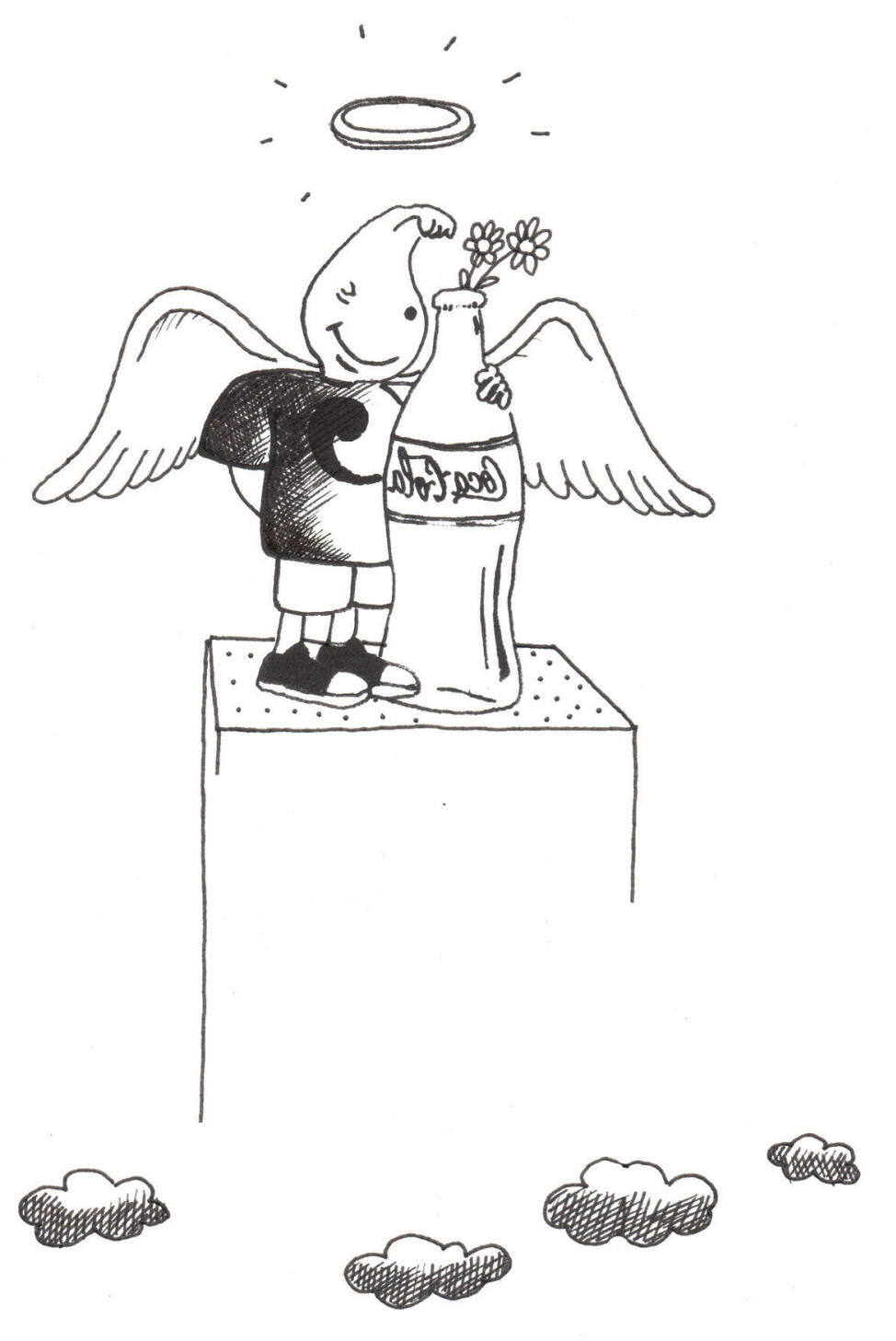




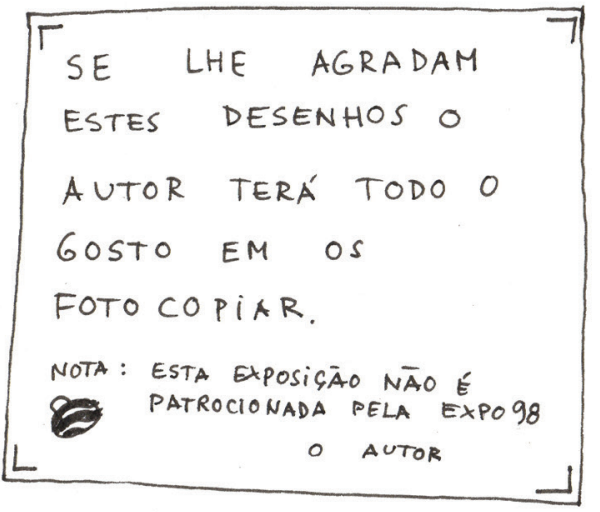

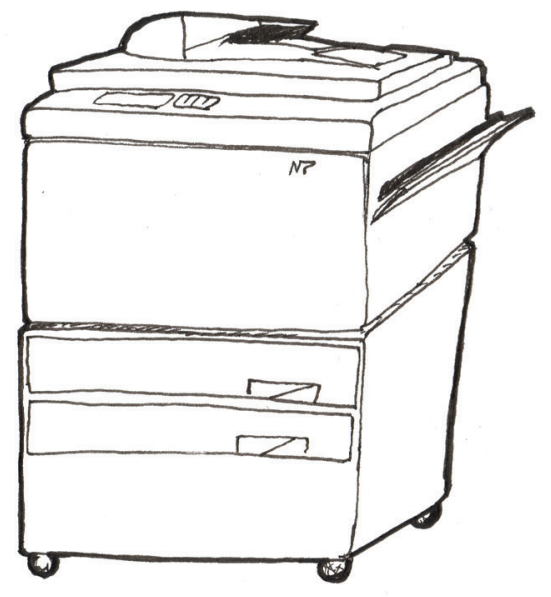

